8. Achim von Arnim und Clemens Brentano. Des Knaben Wunderhorn. Alte deutsche Lieder. Studienausgabe in neun Banden. Herausgegeben von Heinz Rolleke / Achim von Arnim und Clemens Brentano. - Stuttgart: Kohlhammer, 1979. - Band 3. - $828 \mathrm{~s}$.

9. Evangelisches Kirchengesangbuch. - Ausgabe fur die Vereinigte protestanisch Christlishe Kirche der Pfalz.

10. Fourteen Holy Helpers. - Internet resource - Access mode : ru.wikipedia. org/wiki/ Fourteen_Holy_ Helpers

11. Todea Diana. The Opera "Hansel und Gretel" by E. Humperdinck in the primary class / Diana Todea // Neue Didaktik. — 2009. — № 1. - P. 54-74.

УДК 78.03+781.6

Ю. Грибиненко

\title{
ПОЛИСТИЛИСТИЧЕСКИЕ АСПЕКТЫ КОМПОЗИТОРСКОЙ ПОЭТИКИ АЛЬФРЕДА ШНИТКЕ (НА ПРИМЕРЕ КАМЕРНО-ИНСТРУМЕНТАЛЬНЫХ ПРОИЗВЕДЕНИЙ)
}

В статье предлагается общая характеристика камерно-инструментального творчества А. Шнитке. Особое внимание уделяется сонатным произведениям композитора. На их примере раскрываются полистилистические аспекты композиторской поэтики А. Шнитке: устанавливаются ведущие композиционные принципы, формирующие особую авторскую модель полистилистики в творчестве композитора.

Ключевые слова: полистилистика, соната, диалогичность, иитатность, коллаж, аллюзия.

Произведения камерного жанра занимают в творчестве Альфреда Шнитке значительное место; среди них - квартеты, фортепианный квинтет, септет для флейты, двух кларнетов, скрипки, альта, виолончели и клавесина, струнное трио, «Сюита в старинном стиле» для скрипки и фортепиано, «Гимны» и другие произведения для камерного оркестра. Особое место среди камерно-инструментальных произведений композитора принадлежит сонатам - скрипичным, виолончельным, фортепианным. Обращение композитора к этому жанру нельзя назвать частым и постоянным. Первые сонаты были написаны еще в годы его обучения в консерватории, в 1950-х годах: это соната для скрипки и фортепиано и соната для фортепиано (оба

(C) Грибиненко Ю., 2014 
произведения одночастные). В какой-то мере, они определили два основных инструментальных состава, для которых будут создаваться сонаты композитором: это «струнные» (для скрипки и фортепиано, виолончели и фортепиано) и фортепианные произведения.

На протяжении своего творческого пути А. Шнитке пишет три скрипичные сонаты, две виолончельные и две фортепианные. Что же заставляет композитора вновь и вновь обращаться именно к этому жанру, хотя в некоторых интервью он говорит о своей приверженности к более крупным инструментальным формам? Не последнюю роль в выборе жанров произведений сыграло тесное сотрудничество А. Шнитке с выдающимися исполнителями, для которых в большинстве случаев и писались эти сочинения. Скрипичные сонаты посвящены Марку Лубоцкому, виолончельная - Наталии Гутман, фортепианные написаны по просьбе жены Альфреда Гарриевича. «Есть авторы музыки, которые будто пишут музыку для будущего, их музыку могут «открыть» и услышать и через много лет после создания, но есть исполнители, музыканты, творческий путь которых измеряется не очень протяженным временем, ограниченным одной человеческой жизнью. Я пишу для них» [9, с. 46]. Именно так композитор охарактеризовал один из своих творческих принципов.

Главные выразители музыкальных мыслей А. Шнитке - симфонический оркестр, струнный квартет и, что особенно важно для нас, скрипка, альт, виолончель. Фортепиано же занимает у композитора побочное место. Струнные инструменты с их нетемперированностью оказались инструментами XX века, по сравнению с темперированным фортепиано, хотя и рояль композитор использовал «посовременному», в соответствии с новым акустико-гармоническим строем музыки XX века. Это объясняет преобладание «струнных» сонат над фортепианными. И если первые создавались на протяжении всего творческого пути композитора, то вторые появились лишь в конце 1980-х годов, как пополнение исполнительского репертуара жены-пианистки.

Так сложилось, что первые две скрипичные сонаты и виолончельную композитор создавал по одной в периоды творческого становления. Первая соната, написанная в 1963 году, относится к экспериментальному додекафонно-серийному этапу. Следующая скрипичная соната создана пять лет спустя. Именно она явилась одним из первых и наиболее ярких примеров применения полистилистики в советской музыке данного периода. Несмотря на сопоставление стилей в 
шокирующем контрасте, сонорную резкость и новые исполнительские трудности, это произведение стало одним из самых играемых сочинений композитора.

Лишь по прошествии десяти лет А. Шнитке вновь обращается к жанру сонаты, только теперь в ней солирует виолончель. Период создания этого произведения охарактеризован В. Холоповой как период «новой простоты», «тихой музыки», «мемориалов» [6, с. 24]. Трагические события, произошедшие в личной жизни композитора, заставили его посмотреть на многое иными глазами, задуматься о «вечных» вопросах жизни и смерти. Творческим кредо этого этапа можно назвать «потребность сказать просто о сложном, не утратив глубины» [4, с. 40]. С. Савенко подчеркивает, что такие поиски Альфреда Гарриевича в новом направлении характерны не только для него, но и для ряда других отечественных и зарубежных композиторов. «Видимо, - пишет С. Савенко, - это нынешнее направление музыки отражает одну из существенных потребностей искусства XX века» $[4$, с. 42].

Виолончельная соната стоит в центре камерно-инструментального творчества А. Шнитке. Ее отделяет десятилетие от написания Второй скрипичной сонаты и девять лет от фортепианной. В отличие от остальных сонат, она строже, сдержаннее, в ней нет острой экспрессии, большого диапазона контрастов, характерного для композитора образно-эмоционального противостояния, связанного с поэтикой конфликта. Именно она ведет к предельному заострению противоречий при одновременном использовании нескольких стилистических (жанрово-стилистических) комплексов. В этой же сонате заметнее, чем в других, образное и интонационное единство.

Организацию виолончельной сонаты отличает внутренняя сопряженность всех тематических элементов. Создавая из мозаики разнородных мотивов естественные последования, А. Шнитке, столь же естественно, превращает близкие по исходным формулам мотивы в разнородные. Однако этот калейдоскоп движения и завораживающая стихия преобразований, прежде всего, интригуют своей «незаметностью». В этом комбинировании и сопоставлении разнообразных мотивов происходит своего рода «взаимозаменяемость» экспозиционных соотношений, что позволяет говорить об использовании композитором метода стилистической контаминации. Исследователи творчества А. Шнитке отмечают, что «стилистические переходы и оттенки здесь (в виолончельной сонате. - Ю. Г.) подчинены единой 
интонационной логике - это, думается, воистину новая моностилистика» [4, с. 41].

Конец 1980-х годов ознаменовался созданием двух фортепианных сонат. Столь затянутый разрыв между консерваторской сонатой для фортепиано и произведениями, сочиненными приблизительно тридцать лет спустя, можно объяснить отчасти особым отношением композитора к инструменту, а отчасти попыткой еще раз одухотворить форму сонаты. В. Холопова усматривает в этом произведении типичную романтическую сонату. Первая часть представляет собой точную сонатную форму, полную выразительности в духе XIX века с «просветленной, как у Ф. Листа, кодой, в драматической кульминации которой двухлоктевой кластер» [6, с. 48]. Вторая часть сохраняет атмосферу романтизма. В ней противопоставляются «светлые хоралы» и «черные кластеры». Вторая фортепианная соната, также написанная по просьбе жены композитора, упоминается лишь как факт творческой биографии композитора.

Написанная в 1994 году Третья скрипичная соната коронует произведения в камерно-инструментальном жанре и «доказывает» своим появлением, что скрипка была и остается как бы собственным, авторским голосом для композитора, перекрывая по своей важности и информативности другие (нескрипичные) произведения. Интересно, что эта соната создавалась в период завершения работы над оперой «Фауст». По мнению В. Холоповой, тематический материал сочинения перекликается с музыкой этой оперы. Первая часть сонаты - не основная, выполняет функцию пролога и исходит из общих форм движения. Вторая часть характеристична по тематизму, с использованием pizzicato, staccato и броских акцентов. Третья своей обобщенностью перекликается с первой частью, а своей лиричностью снимает напряжение Adagio (II часть). Драматургически необычен финал сонаты, идущий в беспокойном и свободном движении, он обрывается на полуслове. Подобная недосказанность является характерной чертой многих произведений композитора. «В моих сочинениях все часто уходит в многоточие или просто прекращается...»заметил А. Шнитке в беседе с А. Ивашкиным [2, с. 87]. Неосознанно (или сознательно) композитор подчеркивает своими произведениями извечность и неразрешимость конфликта творческой души: «конфликта поэта, который окрашивает жизнь в трагические краски, но который и дает жизнь его творениям» [2, с. 87]. Возможно, это еше раз подтверждает мысль Х. Л. Борхеса о том, что «...существует огра- 
ниченное число историй, циклов, метафор. И назначение человека и культуры в целом - без конца пересказывать их заново, на свой лад, со своей новой интонацией» [1, с. 85].

Сочинением, ставшим одним из первых образцов применения полистилистики в советской музыке, становится Вторая соната для скрипки и фортепиано. Подобно Д. Шостаковичу, А. Шнитке отходит от моностилевого представления о музыкальном языке. Он сам вводит термин «полистилистика», связав его с плюрализмом сознания человека XX столетия, с повышенной интенсивностью информационных потоков в этом столетии. Полистилистика в музыкальной культуре, по его мнению, выполняет ряд смысловых и конструктивных задач:

- усиливает ассоциативный ряд музыки, заменив словесную программность ХIX века;

- осуществляет обогащающий смысловой синтез;

- способствовует демократизации языка, смыканию субкультур ХХ века;

- открывает новые типы музыкальной драматургии и формообразования.

Последнее явление характеризуется многослойностью, полипараметровостью (термин В. Холоповой), разномасштабностью оснований и показывает то состояние формообразования, при котором композитор исходит из индивидуального выбора изобретения, а не из какого-либо общепринятого учения о форме. По этому поводу А. Шнитке заметил, что сейчас «сама идея формы стоит под сомнением как некая неискренняя условность, когда сочинение может быть живым лишь при условии сомнения в форме, когда есть некий риск в форме произведения...» [9, с. 49].

Соната для скрипки и фортепиано № 2 написана в 1968 году - в период «индивидуальных концепций» (В. Холопова). В различных конкретных вариантах А. Шнитке воплощает в произведениях 1960-х классическую дуалистическую драматургию, однако не ограничивается ею, также композитор использует парадоксальную «стилистическую» драматургию в собственной трактовке, а вместе с ней «еще не играную инструментальную концепцию» [5, с. 42]. Все эти черты нашли отражение во Второй скрипичной сонате, интервалика, аккордика которой повышенно диссонантные, будоражащие своей резкостью. По высказыванию самого композитора в этот период его тянуло именно к такой «... агрессивной и диссонантной музыке» [6, с. 43]. 
Подзаголовок сонаты «quasi una Sonata» не случайно перекликается с бетховенским «Sonata quasi una Fantasia». Дело в том, что А. Шнитке ставит себя в позицию, противоположную той, в которой находился Л. Бетховен. Последний творил в период нарастания организованности в музыке, а А. Шнитке - в эпоху, деструктивность которой достигла такого предела, когда формы могут быть очень широко и свободно трактованы. Контуры классической сонаты Л. Бетховена «романтически размыты», а «quasi una Sonata» настолько полемична и «раздираема противоречиями, что не может стать сонатой», по мнению В. Холоповой [6, с. 56].

Но наряду с обширным плюрализмом выражения в скрипичной сонате сохраняются некоторые традиционные черты. Согласно мнению автора, это сомкнутый трехчастный цикл, в котором первая часть построена как сонатная форма с контрастными главной и побочной партиями, с репризой лишь главной партии; вторая часть «нечто вроде медленной части» [6], вереница медленных эпизодов Andantino, Lento, Andante, Moderato andante; третья часть, по мнению В. Холоповой [6, с. 317], «имеет рондообразную структуру с контрастными вторжениями». А. Шнитке усматривает здесь «quasi Fuga» [8, c. 50]. Мы предлагаем говорить в определении структуры финальной части о чертах ричеркара, так как имитационное вступление голосов здесь сочетается с вариационностью.

Музыкальный материал произведения приобретает острый, судорожный, нервный характер. Он образован не развернутыми длинными, а лаконичными мотивами-импульсами. В драматургии сонаты одним из ведущих механизмов является диалогичность. Знаменательно, что А. Шнитке почти никогда не использует в своих произведениях академический прием солирующего и аккомпанирующего инструментов. У него каждый инструмент имеет свой персональный голос, свою, часто диаметрально противоположную традиционной функции инструмента, характеристику, что в очередной раз доказывает: диалогичность - основополагающий фактор мышления А. Шнитке.

В основе концепции сонаты лежит одна из «вечных» идей - конфликт гармонии и дисгармонии. Первая - это «прекрасный идеал, сложившийся в прошлом» [6, с. 60], вторая - современный мир, полный тревог, проблем, противоречий. Музыкальное воплощение эти сферы получают следующим образом: сфера дисгармонии выражена двумя драматическими центрами - аккордом-выстрелом, умень- 
шенным септаккордом и всеми диссонантными построениями, претворяющими своим взаимодействием принцип единства противоположностей; сфера гармонии - хоральная гармонизация темы ВАСН.

В. Холопова выделяет в сонате два драматических центра, представленных структурной музыкой - «арсенал средств раннеклассической музыки» (аккорд g-moll, уменьшенный септаккорд, тема BACH) и деструктурной, «основанной на современных принципах организации звуковысотности». Подобное разделение является, несомненно, одним из возможных вариантов музыковедческой трактовки композиции, но оставляет без внимания еще одно яркое доказательство диалогичности мышления композитора. Доказательство, которое заключено в конфликтной природе современного мира, человека в этом мире: диссонантность, как воплощение проблем, тревог, даже катаклизмов в более широком масштабе, разрешаема устойчивым g-moll'ным аккордом как аллюзией обиходной традиции, канона, несущей надежду на обретение устойчивости в вихре бурной жизни.

Эта идея претворена с первых же тактов сонаты, когда устойчивому аккорду g-moll у фортепиано после продолжительной паузы отвечает такой же яркий на sfff аккорд у скрипки. Главное отличие этих комплексов в том, что второй по звучанию резок, диссонантен, состоит из двух септим. Так как оба драматических центра входят в одну образно-драматургическую сферу дисгармонии, то они в процессе развития не только противостоят друг другу, но и взаимодействуют. Это приводит к проникновению музыкального материала скрипичной партии в фортепианную и наоборот. Так, например, в эпизоде quasi Allegretto кластерным аккордам рояля отвечает мелодическая фраза у скрипки, построенная на звуках g-moll.

Финальная quasi Fuga окончательно утверждает то, что истинно формообразующим моментом в произведении выступает не тематичность сонатного цикла, а сквозное мышление, основанное на других элементах. «Вот, что тема - трезвучие $g$-moll, уменьшенный септаккорд, пауза и цитатность» [9, с. 49]. Эти слова А. Шнитке определяют основополагающие элементы произведения, на рассмотрении которых имеет смысл остановиться подробнее.

1. Аккорд g-moll sfff начинает сонату и на протяжении всего произведения не меняет своего динамического оттенка, что позволило В. Холоповой охарактеризовать это созвучие как «аккорд-выстрел» [6, с. 56]. Созвучие пронизывает всю музыкальную ткань сонаты, играя важную драматургическую роль. Оно появляется во всех зна- 
чительных моментах произведения почти всегда в одном и том же широком расположении, захватывающим крайние регистры. Почти всегда это акцентированная на стаккато тридцать вторая длительность. Интересно, что аккорд является прерогативой партии фортепиано, появляясь у скрипки в виде мелодической попевки по звукам g-moll.

Наиболее ярко борьба в сфере дисгармонии показана в коде, решающем разделе quasi сонаты. Здесь оглушающий поток аккорда g-moll чередуется с кластерами. Это конфликтная борьба происходит на фоне главной партии первой части сонаты, возвращение которой в коде финала хоть и подчеркивает драматургическое единство целого, но не дает окончательного прояснения в конфликте произведения. В последнем проведении, сорок шесть раз повторенный, аккорд g-moll «перечеркивается» внезапно грянувшим на fff кластером. Этому созвучию предстоит замереть на время каденции-послесловия. Стремительные, гневные волны фраз у скрипки содержат реминисценции тематических элементов, участвовавших в развитии сонаты: это серия и уменьшенный септаккорд. Они постоянно прерываются паузами и постепенно исчезают. В последних двух тактах педальный кластер фортепиано снимается и у соло скрипки звучит тема-монограмма. Она соединяет в себе проведение мотива в прямом виде и в обращении, а завершает свое звучание аккордом $g$-moll, изложенным бревисами. Таким образом, окончательный итог борьбы как бы выносится за пределы произведения. Хотя данный в последних тактах сонаты «прекрасный идеал» прошлого совпадает с голосом автора, но звучит так, что в нем проступают «следы разрушительной дисгармонии» [6, с. 59].

2. Уменьшенный септаккорд в полную силу заявляет о себе в разделе, подобном сонатной разработке. До этого момента его прообразы появлялись в скрипичной партии, во вступительном разделе сонаты, а также в первоначальной гармонизации хорала. Это созвучие, по мере достижения кульминации, расширяет свой диапазон и образует полигармонические сочетания, такие как, например: созвучие dis-fis$a-c$ накладывается на $d-f-a s-b$ или ais-cis-e-g на gis- $h-d-f$. Уменьшенный септаккорд, как отмечалось выше, относится к сфере дисгармонии и отражает ее внутреннюю противоречивость, так как наряду с аккордом $g$-moll противостоит диссонантной музыке этой сферы. Оба созвучия являются «основной формулой раннеклассического и классического искусства» [6, с. 32]. 
3. Пауза в сонате несет драматургическое и тематическое значение. Особо важны, как отмечает А. Шнитке, так называемые «внезапные» паузы. Они возникают при нарастании общего напряжения «до невыносимого состояния», при этом «все застывает совершенно неподвижно с тем, чтобы после этого обрушиться и идти дальше» [9, с. 52]. Наиболее ярко эта идея отражена в финальном разделе коды. Интересно, что пауза в этом произведении является также и составной частью темы. Так, например, в самом начале вступления сонаты даются сразу несколько весомых тематических элементов, играющих драматургическую роль: это аккорд $g$-moll, диссонантый аккорд из двух септим, кластерное созвучие и созвучие, в сжатом виде содержащее звуки мотива ВАСН (все они звучат на sfff). На наш взгляд, именно разделение этих элементов паузами помогает осознать их особое назначение в данном произведении, ведь истинное осмысление происходит в тишине. Регламентированность по времени $(6,10,3,5$ секунд) и их репризное проведение (вместе с вышеперечисленными созвучиями) подчеркивает тематическое значение пауз. Интересно, что авторское выписывание протяженности пауз есть только во вступительном разделе, в остальных же случаях применяется знак '. Он является условной единицей отсчета, приблизительно равной $1 / 2$ секунды.

4. Цитатность и аллюзия - наиболее частое применение полистилистического метода в этом произведении. Как отмечает В. Холопова, оба этих приема используются в условиях коллажа, то есть «...резко контрастное сопоставление разнородных стилевых элементов здесь прямо вытекает из общей идеи - показа ожесточенной, непримиримой борьбы» [6, с. 57]. Принцип цитирования А. Шнитке применяет как «цитирование техники» (термин А. Шнитке), что видно на примере аккорда $g$-moll, принадлежащего тональной технике, и как «адаптацию» чужого текста (пересказ чужого нотного текста собственным музыкальным языком). Последнее было применено к цитатам из Л. Бетховена - финала Третьей симфонии и Фортепианных вариаций с фугой оп. 35.

Принцип аллюзии создает в сонате, по мнению В. Холоповой, «самый яркий эффект коллажа» [6, с. 57]. Эти, по словам А. Шнитке, «моменты прикидывания - иностилистические вставки» не являются преобладающей частью произведения, но они достаточно весомы в драматургическом плане. Аллюзии классико-романтической музыки прошлого - Л. Бетховена, Ф. Листа, И. Брамса, С. Франка порождают благодаря узнаванию стилей яркую, наглядную семан- 
тику смысловых представлений. Так, например, мотив-монограмма ВАСН дается в классической хоральной фактуре, в низком регистре, на тихой звучности, что важно в драматургическом плане, потому что именно этот материал составляет сферу гармонии в сонате.

Тема хорала представляет собой вполне традиционную последовательность. Крайние голоса ее зеркально отражают друг друга, что вносит некоторую диссонантность в звучание темы. Первостепенное значение в хорале принадлежит интонации малой секунды. Знаменательно, что до момента появления хорала эта интонация пронизывала всю музыкальную ткань сонаты. Она была завуалирована либо в остинатной фигурации в партии скрипки, либо в акцентированном ходе басового голоса главной партии, либо в тремолирующей каденции скрипки. В заключительной партии мотив-монограмма используется для построения двенадцатитоновой серии. Далее тема ВАСН сжата в одном аккорде (как и во вступительном разделе) и звучит вместе с трезвучием $g$-moll.

В Andantino после изложения ВАСН бревисами (подобно «Сфинксам» Р. Шумана) мотив-монограмма жанрово переодевается и приобретает черты танцевальности - «перевернутое ВАСН звучит в виде вальсика» $[9$, с. 52]. Затем тема сокрыта в «франко-листовской» гармонизации и представляет собой свободный получетвертитоновый речитатив.

B quasi Fuga BACH становится основной темой, которая проводится как в хоральной фактуре, так и в виде имитации. Контраст достигается благодаря включениям в Moderato и Adagio иностилевых фрагментов. Кроме того, что оба они тональны, последний является аллюзией на музыку И. Брамса, с включением в музыкальную ткань его монограммы. Эти иностилевые вставки чередуются с основной темой, которая излагается октавно и приобретает грозный характер.

В переходном к коде разделе мотив ВАСН проходит в ритмическом уменьшении у рояля и перекликается с взлетающим ходом по звукам $b-a^{1}-c^{1}-h^{2}$ в скрипичной партии. Композитор обустраивает так, что наличие на сцене второго рояля с открытой крышкой усиливает резонанс педального кластера первого рояля и создает «особый акустический диалог» - рояль как бы отвечает скрипке [6, c. 59] - ее финальным звукам, представляющим собой глиссандирующий скачок в «никуда» на динамической волне fffpppp. Это позволяет говорить о том, что для А. Шнитке хоральность основывается на восприятии ее как «запредельного звучания голоса». Для мировос- 
приятия композитора является характерным ощущение единства его музыкального сознания с неким «объективным» звуковым пространством, с некоей «метамузыкой», проявляющейся в виде непрекращающегося звукового потока.

Таким образом, внутреннее напряжение образа, фокусирующего внимание на ведущей авторской интонации, сходство различных стилевых модификаций, драматизация и сжатие формы, предельное заострение противоречий при одновременном использовании нескольких жанрово-стилистических комплексов, резкая акцентуация полярных начал и т. д. становятся основополагающими чертами камерно-инструментального творчества А. Шнитке, формирующими особый - центростремительный - тип полистилистики в творчестве композитора.

\section{СПИСОК ЛИТЕРАТУРЫ}

1. Борхес Х. Л. Алеф: Новеллы / Х. Л. Борхес. - СПб. : Азбука, 2000. $544 \mathrm{c}$.

2. Ивашкин А. Беседы с Альфредом Шнитке / А. Ивашкин. - М. : РИК «Культура», 1994. - 304 с.

3. Пантиелев Г. Пять симфоний Альфреда Шнитке / Г. Пантиелев // Советская музыка. - М., 1990. - № 10. - С. 81-87.

4. Савенко С. Портрет художника в зрелости / С. Савенко // Советская музыка. - М., 1981. - № 9. - С. 35-46.

5. Соколов А. Музыкальная композиция XX века. Диалектика творчества / А. Соколов. - М. : Музыка, 1992. - 230 с.

6. Холопова В. Альфред Шнитке : Очерк жизни и творчества / В. Холопова, Е. Чигарева. - М. : Советский композитор, 1990. - 350 с.

7. Хорунженко К. Культурология. Энциклопедический словарь / К. Хорунженко. - Ростов н/Д : Феникс, 1997. - 640 с.

8. Шульгин Д. Альфред Шнитке. Беседы с композитором / Д. Шульгин. - М. : Деловая лига, 1993. - 275 с.

9. Шульгин Д. Годы неизвестности Альфреда Шнитке / Д. Шульгин. М., 1993. - 138 c.

10. Эко У. Отсутствующая структура. Введение в семиологию / У. Эко ; [пер. с ит. В. Резник, А. Погоняйло]. - СПб. : Симпозиум, 2004. - 544 с.

Грібінєнко Ю. Полістилістичні аспекти композиторської поетики Альфреда Шнітке (на прикладі камерно-інструментальних творів). У статті пропонується загальна характеристика камерно-інструментальної творчості А. Шнітке. Особлива увага приділяється сонатним творам композитора. На їх прикладі розкриваються полістилістичні аспекти композиторської поети- 
ки А. Шнітке: встановлюються провідні композиційні принципи, що формують особливу авторську модель полістилістики у творчості композитора.

Ключові слова: полістилістика, соната, діалогічність, цитатність, колаж, алюзія.

Gribinenko G. Polistilistics aspects of the composer's poetics Alfred Schnitke (for example chamber-instrumental works). The article offers a general description of chamber-instrumental works by Alfred Schnitke. Particular attention is paid sonata the composer's works. Their example reveals polistilistics aspects of the composer poetics Alfred Schnitke: the leading established compositional principles, which form a special author polystylistics model in the works of the composer.

Keywords: polystylistics, sonata, dialogue, citation, collage, allusion.

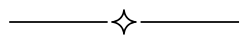

УДК 781.68:78.083.6:78.082.1

\section{O. Сергеева}

\section{К ПРОБЛЕМЕ ИНТЕРПРЕТАЦИИ ЖАНРА ДУМЫ-БАЛЛАДЫ ВО ВТОРОЙ СИМФОНИИ Б. ЛЯТОШИНСКОГО}

Статья посвящена проблеме интерпретации жанра думы-баллады во Второй симфонии Б. Лятошинского. Отмечена родственность жанровой специфики думы и баллады. Обозначен и произведен анализ особенностей проявления феномена композиторской интерпретации жанра думы-баллады во Второй симфонии Б. Лятошинского.

Ключевые слова: дума-баллада, жанр, эпическое, симфония, интерпретация.

Дума-баллада, являясь одной из жанровых разновидностей категории эпического, становится интерпретационным материалом в формировании музыкального текста Второй симфонии Б. Лятошинского.

Исследование данной коммуникативно-жанровой проблематики не получило достаточного освещения в музыковедческой литератуpe. Например, Н. Гордийчук, анализируя Вторую симфонию Б. Лятошинского, указывал на жанр баллады (без последующего выявления подтекста его семантического уровня) через основную мелодию Второй части - «широку, народного складу баладну тему» [3, с. 87]; И. Бэлза о жанре думы-баллады писал следующее: «Но есть во Вто- 